\title{
BMJ Open Measuring safety in older adult care homes: a scoping review of the international literature
}

\author{
Stacey Rand (D) , ${ }^{1}$ Nick Smith, ${ }^{1}$ Karen Jones, ${ }^{1}$ Alan Dargan, ${ }^{1}$ Helen Hogan $^{2}$
}

\begin{abstract}
To cite: Rand S, Smith N, Jones $\mathrm{K}$, et al. Measuring safety in older adult care homes: a scoping review of the international literature. BMJ Open 2021;11:e043206. doi:10.1136/ bmjopen-2020-043206
\end{abstract}

- Prepublication history and additional material for this paper is available online. To view these files, please visit the journal online (http://dx.doi.org/10. 1136/bmjopen-2020-043206).

Received 28 July 2020 Revised 26 January 2021 Accepted 05 February 2021

Check for updates

(C) Author(s) (or their employer(s)) 2021. Re-use permitted under CC BY-NC. No commercial re-use. See rights and permissions. Published by BMJ.

${ }^{1}$ Personal Social Services Research Unit, University of Kent, Canterbury, UK

${ }^{2}$ Department of Health Services Research and Policy, London School of Hygiene \& Tropical Medicine, London, UK

Correspondence to

Dr Stacey Rand;

s.e.rand@kent.ac.uk

\begin{abstract}
Background Safety is a key concern in older adult care homes. However, it is a less developed concept in older adult care homes than in healthcare settings. As part of study of the collection and application of safety data in the care home sector in England, a scoping review of the international literature was conducted.
\end{abstract}

Objectives The aim of the review was to identify measures that could be used as indicators of safety for quality monitoring and improvement in older adult residential or nursing care homes.

Sources of evidence Systematic searches for journal articles published in English language from 1 January 1970 , without restriction to the study location or country, were conducted in Web of Science, Scopus and PubMed on 28 July 2019.

Eligibility criteria Inclusion criteria were: peer-reviewed journal articles; qualitative or quantitative studies of older adult nursing and/or residential care homes; and related to any aspect of safety in care homes, including the safety of healthcare provision in the care home. $A$ total of 45 articles were included after review of the title/abstract or full text against the inclusion criteria.

Charting methods Key information was extracted and charted. These findings were then mapped to the Safety Measurement and Monitoring Framework in healthcare (SMMF), adapted by the research team to reflect the care home context, to determine the coverage of different aspects of safety, as well as potential gaps.

Results and conclusions Systematic searches for journal articles published in English language from 1 January 1970, without restriction to the study location or country, were conducted in Web of Science, Scopus and PubMed on 28 July 2019. Inclusion criteria were: peer-reviewed journal articles; qualitative or quantitative studies of older adult nursing and/or residential care homes; and related to any aspect of safety in care homes, including the safety of healthcare provision in the care home.

A total of 45 articles were included after review of the title/abstract or full text against the inclusion criteria. Key information was extracted and charted. These findings were then mapped to the Safety Measurement and Monitoring Framework in healthcare (SMMF), adapted by the research team to reflect the care home context, to determine the coverage of different aspects of safety, as well as potential gaps.

The findings indicate that there are a range of available safety measures used for quality monitoring and improvement in older adult care homes. These cover

\section{Strengths and limitations of this study}

The study is an international scoping review of safety indicators used in older adult care homes.

- The scoping review was limited to measures reported in peer-reviewed literature, so it may not include safety indicators used at local or regional levels, especially in countries that do not have a national minimum dataset for care homes.

- The psychometric properties and feasibility of data collection of the identified indicators were not evaluated.

all five domains of safety in the SMMF. However, there are potential gaps. These include user experience, psychological harm related to the care home environment, abusive or neglectful care practice and the processes for integrated learning. Some of these gaps may relate to challenges and feasibility of measurement in the care home context.

\section{BACKGROUND}

Safety is a key concern in older adult care homes. (By the term 'care home', we refer to organisations that provide accommodation and 24/7 personal care, eg. support with washing, dressing or taking medicines. It includes institutions staffed by care staff alone (known as residential homes) or with the support of one or more registered nurses on duty (known as nursing homes). Care homes, whether nursing or residential, are widely accepted as distinct from 'extra care', which refers to accommodation and on-site care that expects a greater degree of independent living (eg, assisted living facilities or continuing care retirement communities)). In the context of care homes, both residential and nursing care facilities, as in other health and care settings, safety broadly refers to the absence of preventable harm and the minimisation of unnecessary risk of harm to residents. Common types of physical harm in care homes include injuries as a result of falls, dehydration, pressure ulcers, urinary tract or 
other infections and harm related to failures in medicines management. ${ }^{1}$ Some of these harms may be a result of comorbidity and frailty of residents, which are risks to be managed by responsive and effective care, while other harms may be directly attributable to poor quality or neglectful care, such as omission of care activities or overtreatment. Likewise, some residents may feel unsafe, especially in adapting to the care home environment, or as a result of the behaviour of other residents, ${ }^{2-5}$ which are risks to be managed by care practice. They may also experience psychological harm due to avoidable unsafe care practice that is not respectful of personal dignity.

Improving safety is complex. Lessons from healthcare indicate that, although frontline staff are key to identifying problems and solutions, these activities need to be nested in organisations where leadership, culture and processes support quality improvement and where regional or national governance and regulation priorities and incentives are aligned. ${ }^{6}$ To improve the safety of older adult care homes, it is important to have ways of assessing key aspects of safety informative for quality improvement activity at the individual care home, care home group and regional or national level. Partly because the concept of safety is less well developed in older adult care homes ${ }^{7}$ compared with healthcare settings, ${ }^{8}$ patient safety in healthcare and various approaches to its assessment are adopted by social care. In doing so, however, it is important to carefully consider how healthcare settings differ from care home contexts, which then affects how safety is conceptualised and also considered in practice.

By contrast to other care settings, one of the key distinctive aspects of care homes is that they are places where people live. They are not fully institutional yet also do not offer the privacy of 'home', even though 'homeliness' is valued by residents. ${ }^{9}{ }^{10}$ This introduces a tension between creating a 'homely environment' and also ensuring that residents are protected from risk of harm, like trip hazards or infection control risks presented by soft furnishings. ${ }^{11}$ Furthermore, the focus of the care provided is broader than clinical treatment. The purpose of care is to enable a person to live well by enabling choice, supporting everyday activity and maintaining personal dignity and respect for the person. ${ }^{12}{ }^{13}$ The delivery of personcentred care focuses on individual preferences, wishes and values, and how to respond to those. There may be tensions between an individual's preferences and their safety, or the preferences and safety of other residents. Because care homes residents tend to be at greater risk of harm, abuse or neglect, an important consideration in the delivery of care in residential homes is safeguarding, which refers to adults' rights to live safely, free from harm, abuse and neglect. This is reflected in a sharp focus on safeguarding in this context.

Another consideration is the barriers faced by the care home sector that may make it difficult to embed a culture of reflective learning to drive quality improvement. These barriers vary by country, region or organisation, with differences due to care policy, workforce and cultural or organisational factors. In England, for example, the qualification standards and training opportunities are more limited for the social care workforce compared with the healthcare workforce. Only $68 \%$ of the social care workforce hold any form of relevant qualification. ${ }^{14}$ Therefore, it is arguably more important that the leadership sets the culture of practice, especially as it relates to quality and safety of care, as standards based on prior qualification, training or skills development may not be assumed. Other barriers include the relative isolation of care homes in England, especially for the approximately $30 \%$ of nursing homes in England that are not part of a chain or local authority led, ${ }^{15}$ and the relatively weak links with community healthcare, GPs and other local services. This may make it difficult to access these services on behalf of residents, as well as to work in partnership with those services to deliver good quality and safe care.

A first step towards developing a comprehensive and tailored approach to the assessment of safety in older adult care homes, which reflects the context and needs of the sector, is to understand what aspects of safety are currently measured and how these relate to the key concepts of safety derived from the healthcare setting. This will identify gaps in measurement and also additional context-specific areas where further measures may need to be developed or applied to inform decision making and quality improvement. To this end, a scoping review of international literature was undertaken to identify measures of safety used in older adult care homes.

This scoping review of the international literature was undertaken to identify safety indicators used in older adult care homes, especially those that are likely to inform decision making and quality or safety improvement. These indicators were mapped to the Safety Measurement and Monitoring Framework (SMMF), ${ }^{16}$ a framework of five dimensions relevant to safety monitoring and measurement (harm, reliability, sensitivity to operations, anticipation and preparedness, integration and learning) derived from the healthcare sector but being increasingly applied in care homes. This approach allowed assessment of how well concepts of safety in care homes mirrored those from healthcare and also any gaps in measurement. It took a broad view of safety measurement for quality improvement across different levels from the individual care home, to group, to regional or national level. The review was the initial phase of a wider National Institute for Health Research-funded study of the assessment of safety in care homes in England. The study will subsequently explore the feasibility and challenges of implementing a more systematic approach to collection and application of safety data in the care home sector in England using qualitative methods.

\section{METHODS}

This study applied a five-stage framework for scoping reviews. ${ }^{17}$ Based on the research question (stage 1), systematic searches for articles published in English 
language, without restriction on location/country, from 1970 to 2019, was conducted in Web of Science, Scopus and PubMed on 28 July 2019 to identify literature on the measurement of safety in care homes and/or the application of safety indicators in research, evaluation of quality improvement within care homes. The search terms were "safety" and "care home" or "nursing home" or "residential home" and refined by 'indicator' (see online supplemental file). We chose to focus the searches on 'safety', as a more global term than 'harm', to capture wider concepts and measures suitable to the person-centred care residents, beyond a clinical or healthcare perspective. 'Care home' or 'nursing home' or 'residential home' were applied as terms recognised internationally to refer to residential adult care facilities. Related terms, like 'residential facilities', were not considered as they were too broad and included contexts outside of the scope of the review, like assisted living facilities. The selected time frame (1970-2019) was chosen to consider literature over a longer period to scope any developments in the evidence over that time; however, the majority of articles identified by the searches, and of the articles included in the review presented here, were published since 2000 (stage 2).

The abstract and/or full text of the papers identified through these searches were then each reviewed by two reviewers from the research team (SR, $\mathrm{AD}, \mathrm{KJ}$ and $\mathrm{NS}$ ). Articles were included if they were relevant to the care context (ie, nursing or residential care home for older adults) and topic (safety measurement or monitoring, concepts of safety). Only peer-reviewed journal articles were considered; no further quality constraints or evaluation were applied. The definition of safety included all aspects of safety in care homes, including the safety of healthcare provision, as well as the personal care provided by the care home. Both quantitative and qualitative studies, including research to identify or define concepts as an initial step in measure development, were included.

A total of 45 articles were included (see figure 1) (stage 3). The key information from each paper was then extracted into a summary chart format. The fields included author(s), year, study location, study topic, methodology and the safety indicator(s) used or developed (if applicable) (stage 4). Finally, the results were collated and summarised. The five dimensions of safety monitoring and measurement from the SMMF, ${ }^{16}$ which is a widely recognised framework in healthcare, were reviewed by the research team. The definitions were adapted to reflect the care home context and used as themes to organise the safety measures identified in the literature (stage 5).

\section{Patient and public involvement statement}

The development of the research question and study design was informed by advice and feedback from the public patient involvement advisor for the Quality, Safety and Outcomes Policy Research Unit Safety programme of work.

\section{RESULTS}

The full results of the review are outlined in table 1 . The identified indicators are summarised in table 2, which outlines each of the identified measures against the five dimensions in the SMMF in healthcare. ${ }^{16}$ The findings are further described below with regard to each of the five dimensions: (1) has care been safe in the past; (2) are systems and processes of care reliable; (3) is care safe today; (4) will care be safe in the future; and (5) is the organisation/system responding and improving?

\section{Has care been safe in the past?}

The review identified that commonly used indicators of physical harm in care homes include pressure ulcers, falls, diarrhoeal disease, scabies, malnutrition, dehydration, incontinence, unplanned weight change, urinary tract infections, catheterisation, decline in activities of daily living, experience of pain and mortality. ${ }^{18-35}$ Psychological harm indicators include an individual's sense of self, belonging and connectedness, comfort and security, emotional distress, privacy, respect and autonomy, and dignity. ${ }^{36-39}$

\section{Are systems, processes and behaviour reliable?}

This aspect of safety asks whether the systems, processes and delivery of care, which includes the behaviour and attitude of care staff, offer reliability in keeping residents safe from risk of harm. In the care home context, this includes unsafe or inadequate care that may lead to physical harm. This may be measured as the rate of omission of safety critical care activities, like ambulation, turning, feeding, personal hygiene or surveillance. ${ }^{40}$ The quality of information held in care records, which is used to guide the delivery of care, may also be considered as an indicator of process reliability, ${ }^{41}$ and a number of medication-related measures were identified as indicators of the failure of safety-critical processes: for example, incidence of inappropriately prescribed medicines, ${ }^{42-44}$ medication errors, ${ }^{45}$ psychotropic prescribing for people with dementia, ${ }^{46}$ medication review rates and failure to use medication. ${ }^{47}$

The reliability of the system of a care home has also been conceptualised in terms of its physical environment. Whether there is adequate lighting and ventilation, for example, may influence the risk of falls or infectious respiratory disease. The physical environment also needs to facilitate infection control procedures and other safety critical processes but also be sufficiently 'homely' to prevent psychological harm. The reliability of the care home environment may also interact with behaviours within the system: for example, the design and use of space may affect space for privacy or inability to protect residents from intrusive noise, as well as also how care is delivered by staff in the space. In three of the studies, 


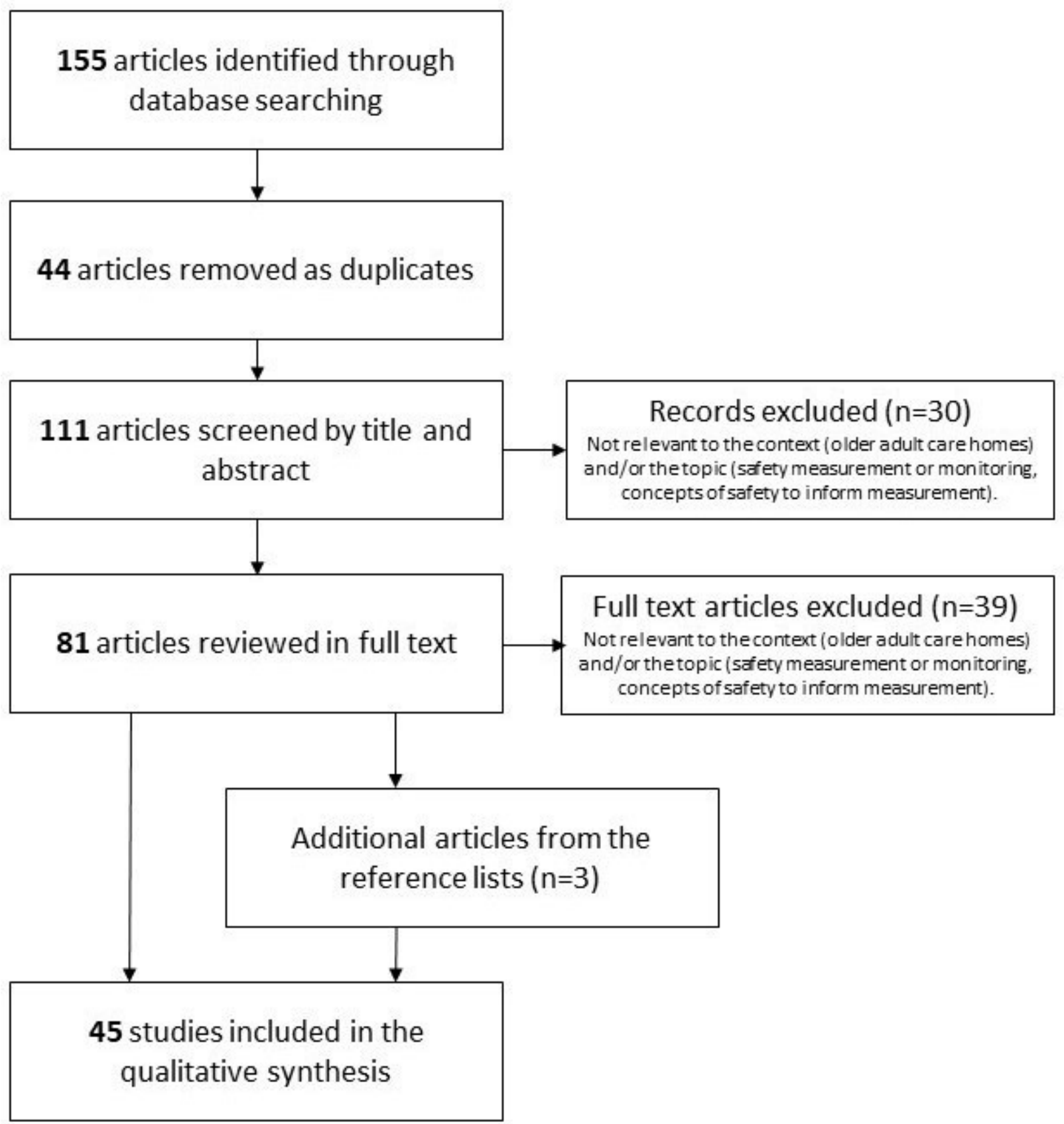

Figure 1 Literature search.

aspects of the physical environment of care homes or its social/functional use were considered as safety indicators. $^{36} 3839$

\section{Is care safe today?}

Approaching the question of whether care is safe now from the residents' perspective is a well-established approach in care home contexts. Indeed, feeling safe has been identified as a key aspect of care home quality. ${ }^{48}$ One approach asks residents to describe qualitatively how safe they feel. More common though is to measure how safe residents feel quantitatively. The quantitative approaches often place the safety indicator within a wider set of questions, some of which may be related to safety, but also focus, more generally, on user experience and/or quality of life. An example of a resident-reported indicator of safety is from the Adult Social Care Outcomes Framework (ASCOF) in England, which solely focuses on userreported safety without any further harm-related safety indicators. ${ }^{49}$ The ASCOF domain of safeguarding adults includes two indicators: (1) ASCOF 4A, an overarching measure of the proportion of people who use services (including care homes) who feel safe and (2) ASCOF 4B, the proportion of people who report services have made them feel safe. ASCOF 4A is measured using one of the eight items from the Adult Social Care Outcomes Toolkit (ASCOT), a social care-related quality of life instrument 
Table 1 Literature review findings

\begin{tabular}{|c|c|c|c|c|}
\hline Authors (year) & Location & $\begin{array}{l}\text { Type of study/ } \\
\text { methodology }\end{array}$ & Topic & Safety indicators \\
\hline Aronovitch (2006) ${ }^{26}$ & USA; Australia & Narrative literature review. & $\begin{array}{l}\text { Risk factors associated with } \\
\text { falls. }\end{array}$ & Number of falls. \\
\hline Bonner et al ${ }^{63}$ (2008a) & USA & $\begin{array}{l}\text { Secondary analysis } \\
\text { (quantitative). }\end{array}$ & $\begin{array}{l}\text { Relationship between nursing } \\
\text { assistant perception of safety } \\
\text { and clinical outcomes. }\end{array}$ & $\begin{array}{l}\text { Hospital Survey of Patient Safety } \\
\text { Culture (HSOPSC); falls, pressure } \\
\text { ulcers and daily restraint. }\end{array}$ \\
\hline Bonner et $a l^{28}$ (2008b) & USA & Literature review & $\begin{array}{l}\text { Review of literature on patient } \\
\text { safety culture in nursing } \\
\text { homes. }\end{array}$ & $\begin{array}{l}\text { HSOPSC; Shortell organisation } \\
\text { and management survey; Safety } \\
\text { Attitudes Questionnaire (SAQ). }\end{array}$ \\
\hline Brazil et $\left.a\right|^{56}(2012)$ & Canada & Qualitative study & $\begin{array}{l}\text { The views of decision makers } \\
\text { about quality of care within } \\
\text { long-term care homes to guide } \\
\text { improvement in the quality of } \\
\text { care in long-term care homes. }\end{array}$ & $\mathrm{n} / \mathrm{a}$ \\
\hline Cavalcante et al ${ }^{18}$ (2016) & Brazil & $\begin{array}{l}\text { Secondary analysis } \\
\text { (quantitative). }\end{array}$ & $\begin{array}{l}\text { Prevalence of key safety } \\
\text { indicators nursing homes. }\end{array}$ & $\begin{array}{l}\text { Mortality rate; incidence of } \\
\text { diarrhoeal diseases and scabies; } \\
\text { prevalence of pressure ulcers; and } \\
\text { falls (with or without injury). }\end{array}$ \\
\hline Cranley et a/ ${ }^{69} 2011$ & Canada & Tool development. & $\begin{array}{l}\text { Evaluate the feasibility of } \\
\text { engaging frontline staff to use } \\
\text { quality improvement methods } \\
\text { to integrate best practices into } \\
\text { resident care. }\end{array}$ & $\begin{array}{l}\text { Safer Care for Older Persons (in } \\
\text { residential) Environments. }\end{array}$ \\
\hline Estabrooks et al ${ }^{30}$ (2016) & Canada & $\begin{array}{l}\text { Secondary analysis } \\
\text { (quantitative). }\end{array}$ & $\begin{array}{l}\text { Presentation of complex data } \\
\text { on nursing homes to non- } \\
\text { research stakeholders. }\end{array}$ & $\begin{array}{l}\text { Alberta Context Tool (ACT); } \\
\text { urinary tract infection (UTI) and } \\
\text { indwelling catheter from the } \\
\text { Resident Assessment Instrument - } \\
\text { Minimum Data Set (RAI-MDS) 2.0. }\end{array}$ \\
\hline Estabrooks et al ${ }^{65}$ (2016) & Canada & Tool development & Development of the ACT. & ACT. \\
\hline Fleming $^{38}(2011)$ & Australia & Tool development. & $\begin{array}{l}\text { To compare an assessment } \\
\text { tool developed for use in } \\
\text { home-like environments (the } \\
\text { Environmental Audit Tool } \\
\text { (EAT)), with the gold standard } \\
\text { assessments for residential } \\
\text { facilities for people with } \\
\text { dementia, the Special Care } \\
\text { Unit Environmental Quality } \\
\text { Scale and the global score } \\
\text { of the Therapeutic Screening } \\
\text { Survey for Nursing Homes. }\end{array}$ & EAT. \\
\hline
\end{tabular}


Table 1 Continued

\begin{tabular}{llll}
\hline Authors (year) & Location & $\begin{array}{l}\text { Type of study/ } \\
\text { methodology }\end{array}$ & Topic \\
\hline Fleming et $\mathrm{a}^{36}(2017)$ & $\mathrm{n} / \mathrm{a}$ & Narrative literature review. & $\begin{array}{l}\text { A review on the concept } \\
\text { of home and the common } \\
\text { measures taken to address } \\
\text { homeliness in a care home } \\
\text { setting. }\end{array}$ \\
& & \\
& &
\end{tabular}

Gartshore et $\mathrm{al}^{7}$ (2017) n/a Scoping literature review. Patient safety culture in older adult care homes.

$\begin{array}{lll}\text { Greenberg et } a 1^{19} \text { (2009) } & \text { n/a }\end{array}$

Review of data on patient Review of data on patient safety indicators.

Tool development/ evaluation. safety indicators. quality (including in care

\begin{tabular}{|c|c|c|c|c|}
\hline Hillen et al ${ }^{47}$ (2015) & $n / a$ & $\begin{array}{l}\text { Systematic literature } \\
\text { review. }\end{array}$ & $\begin{array}{l}\text { The evaluation of medication- } \\
\text { related quality of care in older } \\
\text { adult care homes. }\end{array}$ & $\begin{array}{l}\text { Various ( } 28 \text { indicators from } 22 \\
\text { datasets). }\end{array}$ \\
\hline HSOPSC User Guide ${ }^{64}$ & USA & Tool user guide. & $\mathrm{n} / \mathrm{a}$ & HSOPSC. \\
\hline Hsieh et $a l^{39}$ (2012) & Taiwan & Delphi study. & $\begin{array}{l}\text { Developing indicators of } \\
\text { environmental quality in long } \\
\text { term care facilities. }\end{array}$ & $\mathrm{n} / \mathrm{a}$ \\
\hline Johnsen et a/ ${ }^{57}$ (2016) & USA & $\begin{array}{l}\text { Work system framework } \\
\text { analysis. }\end{array}$ & Staff levels in nursing homes. & $\begin{array}{l}\text { Nursing staffing levels and care } \\
\text { deficiencies. }\end{array}$ \\
\hline Kim et al ${ }^{59} 2009$ & USA & $\begin{array}{l}\text { Secondary analysis } \\
\text { (quantitative). }\end{array}$ & Staff levels in nursing homes. & $\begin{array}{l}\text { Staffing levels and care } \\
\text { deficiencies. }\end{array}$ \\
\hline Mamun et al ${ }^{44} 2004$ & Singapore & Case note review. & $\begin{array}{l}\text { Assessing polypharmacy } \\
\text { and inappropriate medicine } \\
\text { in older adult care home in } \\
\text { Singapore. }\end{array}$ & $\begin{array}{l}\text { The frequency of polypharmacy, } \\
\text { inappropriate medication and } \\
\text { medication incidents extracted } \\
\text { from case notes. }\end{array}$ \\
\hline
\end{tabular}

Developing domains of care homes) that balance validity, appropriateness, feasibility and consensus (experts and consumers).

Continued

None, although it draws on two customer satisfaction instruments and two tools used by Dutch inspectorate.

Safety indicators

$\mathrm{n} / \mathrm{a}$

Nursing Home Survey of

Patient Safety Culture, SAQ, Communicating, About Nursing Errors survey, Accreditation Canada's Patient Safety Culture Tool, Community Living Centres Employee Survey on Attitudes about Resident Safety, Patient Safety Climate Survey, and Safety Organizing Scale.

Prevalence of falls and incidence of pressure ulcers. 
Table 1 Continued

\begin{tabular}{|c|c|c|c|c|}
\hline Authors (year) & Location & $\begin{array}{l}\text { Type of study/ } \\
\text { methodology }\end{array}$ & Topic & Safety indicators \\
\hline Marlin et $a l^{24}$ (1999) & USA & $\begin{array}{l}\text { Literature review; } \\
\text { secondary analysis } \\
\text { (quantitative). }\end{array}$ & $\begin{array}{l}\text { Review of literature to examine } \\
\text { the relationship between } \\
\text { strategic groups membership } \\
\text { and performance in the } \\
\text { nursing. }\end{array}$ & $\begin{array}{l}\text { Pressure sore rate, unplanned } \\
\text { weight changes, use of restraints } \\
\text { and catheterisation rates. Health } \\
\text { and life and safety deficiencies } \\
\text { based on the number and type(s) } \\
\text { of deficiency identified during } \\
\text { each facility's recertification } \\
\text { survey. }\end{array}$ \\
\hline
\end{tabular}

\begin{tabular}{|c|c|c|c|}
\hline Mueller and Karon ${ }^{22}$ (2003) & USA & Quantitative study. & $\begin{array}{l}\text { Explore the opinions of long- } \\
\text { term care nursing experts } \\
\text { about the American Nurses } \\
\text { Association (ANA) nurse } \\
\text { sensitive quality indicators and } \\
\text { their relevance to long-term } \\
\text { care. }\end{array}$ \\
\hline Norton et al ${ }^{20}(2014)$ & Canada & Tool development. & $\begin{array}{l}\text { To demonstrate the benefit } \\
\text { of defining operational } \\
\text { management units in nursing } \\
\text { homes and computing quality } \\
\text { indicators on these units as } \\
\text { well as on the whole facility. }\end{array}$ \\
\hline
\end{tabular}

Nurse sensitive quality indicators developed through the ANA's Safety and Quality Initiative, including frequency of pressure ulcers, falls, patient satisfaction, staff ratios, nursing care hours and staff satisfaction.

Quality indicators derived from the RAI-MDS 2.0 quality indicators for: PRU05-prevalence of residents with stage $2-4$ pressure ulcers, PAIOX (prevalence of residents with pain) and DRG01 (prevalence of residents receiving an antipsychotic with no diagnosis of psychosis).

\begin{tabular}{|c|c|c|c|c|}
\hline O'Connor et al/3 (2012) & $\mathrm{n} / \mathrm{a}$ & Literature review. & $\begin{array}{l}\text { Review to describe the } \\
\text { inappropriate prescribing } \\
\text { detection tools or criteria } \\
\text { most frequently cited in } \\
\text { the literature and examine } \\
\text { their role in preventing } \\
\text { inappropriate prescribing } \\
\text { and other related healthcare } \\
\text { outcomes. }\end{array}$ & Inappropriate prescribing tools. \\
\hline Oetjen et $a^{23}(2011)$ & USA & $\begin{array}{l}\text { Secondary analysis } \\
\text { (quantitative). }\end{array}$ & $\begin{array}{l}\text { The relationship between } \\
\text { financial performance and } \\
\text { selected safety measures } \\
\text { of nursing homes (food } \\
\text { sanitation, records complete, } \\
\text { accuracy of assessment, } \\
\text { assessment by qualified } \\
\text { staff, drug storage, pharmacy } \\
\text { procedures, infection control } \\
\text { and medication errors greater } \\
\text { than } 5 \% \text { and unnecessary } \\
\text { drugs). }\end{array}$ & $\begin{array}{l}\text { Nine safety measures from the } \\
\text { Online Survey, Certification and } \\
\text { Reporting data. }\end{array}$ \\
\hline Parker et al (2019) $)^{80}$ & USA & Qualitative interview study. & $\begin{array}{l}\text { Staff perception of the conflict } \\
\text { between person-centred care } \\
\text { and safety. }\end{array}$ & $\mathrm{n} / \mathrm{a}$ \\
\hline Pickering et a/ ${ }^{66}$ (2017) & USA & Telephone interviews. & $\begin{array}{l}\text { Exploring how the certified } \\
\text { nursing assistants understand } \\
\text { and responds to bullying in the } \\
\text { workplace. }\end{array}$ & $\begin{array}{l}\text { Institutional culture and care staff } \\
\text { outcomes related to bullying } \\
\text { behaviour, for example, inflicting } \\
\text { overload, mishandling critical } \\
\text { incidents, playing favourites, } \\
\text { belittling staff, bullying and/or } \\
\text { putting residents at risk. }\end{array}$ \\
\hline
\end{tabular}


Table 1 Continued

\begin{tabular}{|c|c|c|c|c|}
\hline Authors (year) & Location & $\begin{array}{l}\text { Type of study/ } \\
\text { methodology }\end{array}$ & Topic & Safety indicators \\
\hline $\begin{array}{l}\text { Scott-Cawiezell and } \\
\text { Vogelsmeier }^{35}(2000)\end{array}$ & $\mathrm{n} / \mathrm{a}$ & Literature review. & $\begin{array}{l}\text { A review of safety in older } \\
\text { adult nursing homes (2005- } \\
\text { 2010). }\end{array}$ & $\begin{array}{l}\text { Center for Medicare \& Medicaid } \\
\text { Services Quality Indicators and } \\
\text { Quality Measures, that is, falls, } \\
\text { use of physical restraints, pressur } \\
\text { ulcers and infections. }\end{array}$ \\
\hline
\end{tabular}

Stevenson et $\left.a\right|^{25}$ (2013)

USA

Secondary analysis (quantitative).

\begin{tabular}{lll}
\hline Trinkoff et $a l^{34}$ (2014) & USA & $\begin{array}{l}\text { Secondary analysis } \\
\text { (quantitative). }\end{array}$ \\
\hline van Gaal et $a l^{32}(2009)$ & The Netherlands & $\begin{array}{l}\text { Develop and test a patient } \\
\text { safety programme. A } \\
\text { cluster randomised trial. }\end{array}$
\end{tabular}
cluster randomised trial.
To assess whether the experience of being sued and incurring litigation costs affects the quality of care subsequently delivered in nursing homes.

Associations of education and certification among nursing home administrators and director of nursing with residents outcomes.

Develop and test an integral patient safety programme that addresses three adverse events: pressure ulcers, falls and UTIs.

\begin{tabular}{lll}
$\begin{array}{l}\text { van Nie-Visser et } a l^{31} \\
\text { (2013) }\end{array}$ & The Netherlands & $\begin{array}{l}\text { Annual cross-sectional } \\
\text { multicentre point } \\
\text { prevalence survey. }\end{array}$ \\
\hline Vermeulen et $a l^{45}(2017)$ & The Netherlands & Interview study. \\
Wells et $a f^{55}(2019)$ & Australia & Tool development. \\
& & \\
Winters et $a l^{53}$ (2014) & The Netherlands & Cross-sectional study.
\end{tabular}

van Nie-Visser et $a l^{31}$

et $a /^{53}(2014)$

\section{An international prevalence measurement of care problems: study protocol.}

Understanding the impact of supervision on reducing medication risks: an interview study in long-term elderly care.

Development of an interview tool to be implemented by the Australian Aged Care Quality Agency in residential aged care as a quality indicator.

The influence of corporate structure and quality improvement activities on outcome improvement in residential care homes.
Incidence of pressure ulcers, use of physical restraints, activity of daily living (ADL) decline, UTIs and violations of safe care that involved actual harm or jeopardy to residents.

Pressure ulcers, urinary tract infection and pain.

Inpatient safety programme for the prevention of adverse events (pressure ulcers, UTI and falls). Secondary outcome measures was the utilisation of preventive interventions and the knowledge of nurses regarding the three topics (pressure ulcers, UTI and falls).

LPZ-International. This includes incidence of care problems, use of physical restraints, incontinence, malnutrition, pressure ulcers and falls.

Medication safety incidents (selfreported).

Consumer Experience Report.

Resident-reported indicators, including shared decision making, availability of information, meals, competency and safety, comfort, atmosphere, housing and privacy activities, safe living environment and availability/attitudes of care staff.

Other indicators (reported by professionals/care staff), including incidence of falls, medicine incidents, psychopharmacy, antidepressants, problem behaviour and depression.

\begin{tabular}{|c|c|c|c|c|}
\hline Xu et al ${ }^{33}$ (2019) & USA & $\begin{array}{l}\text { Secondary analysis } \\
\text { (quantitative). }\end{array}$ & $\begin{array}{l}\text { Examine the relationship } \\
\text { between quality indicators and } \\
\text { preventable hospitalisation. }\end{array}$ & $\begin{array}{l}\text { Indicators from the Minnesota } \\
\text { Nursing Home Report Card } \\
\text { and resident-level variables } \\
\text { from the MDS, including the } \\
\text { use of antipsychotics (without } \\
\text { a diagnosis of psychosis), } \\
\text { unexplained weight loss, } \\
\text { UTIs, pressure ulcers, bladder } \\
\text { continence and ADL dependence. }\end{array}$ \\
\hline
\end{tabular}


Table 1 Continued

\begin{tabular}{lllll}
\hline Authors (year) & Location & $\begin{array}{l}\text { Type of study/ } \\
\text { methodology }\end{array}$ & Topic & Safety indicators \\
\hline Yeung and Chan ${ }^{61}(2012)$ & Hong Kong. & Questionnaire survey. & $\begin{array}{l}\text { Measuring safety climate in } \\
\text { elderly homes. }\end{array}$ & $\begin{array}{l}\text { Occupational Safety and Health } \\
\text { Council (OSHC) safety climate tool } \\
\text { (modified). }\end{array}$ \\
Yu and Qian ${ }^{41}(2018)$ & Australia & Tool development. & $\begin{array}{l}\text { Developing a theoretical } \\
\text { model and questionnaire } \\
\text { survey instrument to measure } \\
\text { the success of electronic } \\
\text { health records in residential } \\
\text { aged care. }\end{array}$ & $\begin{array}{l}\text { Training, self-efficacy, system } \\
\text { quality, information quality, user } \\
\text { usen and net benefits of }\end{array}$ \\
\hline
\end{tabular}

(ASCOF 1A). ${ }^{50-52}$ Focusing on the residents' perspective on safety can be found in other tools too, including the Dutch national indicator set, the Consumer Quality Index $^{53} 54$ and the Consumer Experience tool, which forms part Australian Aged Care Quality Agency audit process to capture residents' experience of care quality. ${ }^{55}$

Will care be safe in the future?

In asking whether care will be safe in the future, the review identified safety indicators that relate to organisational and wider contextual factors, including staffing and safety culture within individual or groups of care homes, as well as wider systems-level factors, such as the funding of long-term care systems, ${ }^{56}$ for-profit care ${ }^{57}$ and market-level factors, ${ }^{58}$ that influence future risk of harm within an individual home or the residential care sector.

The literature review identified the skill, experience and number of care home staff per resident as potential indicators. These factors are related to the incidence of both care deficiencies and harm-related safety indicators. ${ }^{57}$ Other studies focused on patient safety culture (PSC) and/or the quality of the workplace environment as safety indicators. PSC refers to a combination of individual and group values, perceptions, attitudes, competencies and behaviours that influence an organisation's safety management style. ${ }^{60}$ The PSC measures identified in the literature review include the Occupational Health

Table 2 Measures of safety

Dimension Measures/indicators of safety

\section{Harm}

Has care been safe in the past? (What are the rates of past harm?)
Physical harm: occurrence of pressure ulcers, falls, diarrhoeal disease or scabies, malnutrition, dehydration, incontinence, unplanned weight change, catheterisation, urinary tract infections, decline in activities of daily living, experience of pain and mortality.

Psychological harm: measures of an individual's sense of self, connectedness, and belonging, comfort and security, emotional distress, privacy, respect and autonomy, and dignity.

\section{Reliability}

Are systems, processes and behaviour reliable?

(Indicators of the reliability of safety critical processes and systems, and also the capacity of staff to follow safety critical procedures.)

Omission of safety critical care activities, for example, ambulation, turning, feeding, personal hygiene or surveillance. medication errors, psychotropic prescribing for people with dementia, failure to use medication and occurrence of medication review.
Medication-related measures, for example, inappropriately prescribed medicines,

Physical environment of the care home, for example, adequacy of lighting and ventilation, sterile or clinical environment (lack of 'homeliness').

Social use of the care home environment, for example, lack of space for privacy, or intrusive noise with the potential to cause psychological harm.

How care is delivered in the space, for example, are rooms large enough for safe use of equipment and lack of space for delivery of care with dignity and respect. Care record keeping. Is key care-related information captured adequately?

\section{Sensitivity to operations}

Is care safe today?

Anticipation and preparedness *
Will care be safe in the future?
(The ability to anticipate, and be prepared for, problems and
threats to safety.)

\section{Integration and learning}

Are we responding and improving?

(The capacity to collect, analyse and improve from, safety

information.)
Resident reports of feeling safe or other safety-related aspects of user experience.

Staffing levels, skill or training.

Patient safety culture.

The use of national or regional datasets that include safety indicators for monitoring and improvement, for example, Resident Assessment Instrument Minimum Data Set 2.0.

${ }^{*}$ This may also be influenced by wider systems-level contextual factors, including administration, policy and funding. 
and Safety Council Safety Climate Questionnaire ${ }^{61}$ the Nursing Home Survey on Patient Safety Culture, ${ }^{58} 62$ which is an adapted version of the Hospital Survey on Patient Safety Culture, ${ }^{286364}$ and the Alberta Context Tool, which captures a range of quality and safety-related contextual factors. ${ }^{30} 65$ Studies have found that PSC is lower in nursing homes than in hospitals, with lower levels of learning from errors, less open communication and a blaming or punitive culture among staff. ${ }^{28}$

These workplace-level indicators may be important, as it has been found that work environment influences resident safety outcomes more than the traits of individual care staff. ${ }^{66}$ They may also be important sources of additional information to support the interpretation of harm-based indicators: for example, it has been found that good PSC is related to lower reporting of some harmbased safety indicators ${ }^{58}$ but higher reporting of others (eg, report of falls), likely due to more accurate reporting and/or differences in care practice, for example, reduced use of restraints. ${ }^{63}$

\section{Are we improving and responding?}

The literature on measuring safety in care homes referred to various measures included in national datasets for quality monitoring and improvement. Examples include the National Prevalence Measurement of Quality of Care (the 'LPZ'), which is collected annually in the Netherlands $^{29}$ and the Resident Assessment Instrument Minimum Data Set 2.0, which has been adapted and applied to national-level quality monitoring of care facilities in Canada. ${ }^{67}$ The US Agency for Healthcare Research Quality collects and reports indicators of harm as part of the Minimum Data Set 3.0 for nursing homes ${ }^{19} 68$ and the Brazilian National Health Surveillance Agency ('ANVISA') requires monthly reporting of indicators. ${ }^{18}$ The principle of this approach is to monitor overall safety and quality with a systems-level view. To translate these data into the improvement of the quality and safety, however, it is important to consider the steps required in practice.

Studies looking at this area have identified some common essential elements that enable learning in the care home context. This includes local and specific measurement, either at the unit of the whole care home and/or staff team led by the same leader, or at the resident level, that is linked to staff learning via intentional activities, like networking, ${ }^{2069}$ and also supported by clinical expertise and quality improvement methods within the team. ${ }^{21}$ While these elements are commonly found in healthcare teams, as they review and learn from safety incidents, they are not usually commonplace in the care home context. ${ }^{28}$

\section{DISCUSSION}

A scoping review was undertaken to identify safety indicators used in older adult care homes from the international literature. How these relate to the key concepts of safety derived from healthcare settings was determined by mapping onto the the five dimensions of safety in the SMMF. $^{16}$

In reviewing the literature, there are a wide range of potential measures already available, but there are also some potential gaps and challenges related to data collection and application in the care home context. Measures of past harm identified in the literature have mirrored those used in clinical settings and are dominated by measures of physical rather than the psychological harm. This may not adequately reflect the person-centred focus of care in care home settings and the potential for harm from care delivered in a way that does not respect a person's dignity or personal preferences. Similarly, the assessment of reliability of systems, processes and behaviours has focused on safety critical processes, such as ambulation. One could argue that freedom from psychological harm and a safe, but homely, physical environment should play a more significant role in safety assessment when the care environment represents 'home' for its residents. The qualities of 'homeliness', with access to individualised space and personalised décor, and also relationships with other residents contribute to a sense of (in) security and (not) feeling safe. ${ }^{10}$

Social care tends to place a greater emphasis on the views and experience of people, which reflects its aim of promoting the quality of life. ${ }^{50}$ Using residents' views and self-reported outcome measures should, therefore, be an integral part of understanding and measuring safety. This approach, however, presents a challenge. The prevalence of cognitive impairment among care home residents often precludes the use of traditional data collection methods for self-report measures. ${ }^{70-75}$ The use of proxy report by care staff and/or family carers, as in the care home version of ASCOT, ${ }^{1276}$ may also be problematic due to potential bias, even if it may be preferable to systematic exclusion from data collections. ${ }^{77-79}$ Further research on safety data collection methods in care homes is required to adequately address these concerns. A gap also exists in adequately capturing information on the incidence of abusive or neglectful care practice. There are complex issues as to whether, and how, such sensitive data might be reliably collected through resident report, staff report (self or colleague) and/or staff observation.

To date, there is relatively little evidence of learning in practice from safety metrics within care home staff teams, especially learning that directly involves care workers and managers. There is also limited insight into potential barriers to learning presented by care sector conditions (eg, staffing levels, employment conditions and the professional status of care workers) and ways to adapt practice-based processes in light of these contextual differences. Improvement targeted at either systems level or organisational level is also relatively underdeveloped in the care home sector. Such monitoring is likely to require a dual individual organisational perspective, since measures of contextual factors, including PSC, offer important contextual evidence to guide the 
interpretation of individual-level harm-based indicators, as well as the ways in which an organisation is led and responds to safety challenges.

Wider systems-level factors are generally considered in the literature as influences on safety, rather than as measures of safety. This approach acknowledges the influence of such factors on care home safety and quality; however, it also implies that these wider factors are beyond the scope of quality improvement interventions. The extent to which policy and funding models influence the quality and safety of care remains a gap in the literature. Further evidence could establish the degree of influence of these factors, as well as suitability as safety indicators to understand, guide and improve safety at a systems level.

A limitation of this study is that its approach focused on measures found in the international peer-reviewed literature. It is possible that indicators used in practice were omitted, especially in countries, like England, that do not have a national minimum dataset for care homes and where fragmented local practice is unlikely to be reported in peer-reviewed literature. Further investigation of safety measurement and improvement within care homes and consortia, and undertaken by adult social care quality monitoring teams, safeguarding managers, commissioners and other stakeholders within local authorities or regional bodies in England, would contribute to the evidence base. This is the next phase of work of the study of which this scoping review is part. An evaluation of the psychometric properties of indicators (ie, reliability, validity and ability to differentiate between good and poor quality care) would also be a useful contribution. There are also important considerations as to whether it is feasible to routinely collect the required data in the resource-constrained residential home environment. Further work is needed before measurement systems are in place that can fulfil these criteria.

In summary, this scoping review has identified safety indicators collected and used in older adult care homes from the international literature. These indicators have been evaluated and analysed against the $\mathrm{SMMF}^{16}$ to identify gaps and areas where adaptation may be required to adequately capture safety in the context of older adult care homes. Some of the key contextual differences and challenges have been considered.

Contributors All authors contributed to the study design and development of the research question. SR, AD, NS and KJ developed and refined the search strategy, reviewed the articles and summarised the findings. SR drafted the manuscript, with review and approval by all coauthors. We would also like to acknowledge and thank Anica Alvarez Nishio, the Public Patient Involvement advisor for the Safety programme of Quality, Safety and Outcomes Policy Research Unit, for her contribution to the study.

Funding This work was supported by the National Institute for Health Research Policy Research Programme, grant number PR-PRU-1217-20702.

Disclaimer This research was funded by the National Institute for Health Research (NIHR) Policy Research Programme, conducted through the Quality, Safety and Outcomes Policy Research Unit (QS0-PRU), PR-PRU-1217-20702. The views expressed are those of the author(s) and not necessarily those of the NIHR or the Department of Health and Social Care.

Competing interests None declared.
Patient consent for publication Not required.

Provenance and peer review Not commissioned; externally peer reviewed.

Data availability statement No data are available.

Supplemental material This content has been supplied by the author(s). It has not been vetted by BMJ Publishing Group Limited (BMJ) and may not have been peer-reviewed. Any opinions or recommendations discussed are solely those of the author(s) and are not endorsed by BMJ. BMJ disclaims all liability and responsibility arising from any reliance placed on the content. Where the content includes any translated material, BMJ does not warrant the accuracy and reliability of the translations (including but not limited to local regulations, clinical guidelines, terminology, drug names and drug dosages), and is not responsible for any error and/or omissions arising from translation and adaptation or otherwise.

Open access This is an open access article distributed in accordance with the Creative Commons Attribution Non Commercial (CC BY-NC 4.0) license, which permits others to distribute, remix, adapt, build upon this work non-commercially, and license their derivative works on different terms, provided the original work is properly cited, appropriate credit is given, any changes made indicated, and the use is non-commercial. See: http://creativecommons.org/licenses/by-nc/4.0/.

ORCID iD

Stacey Rand http://orcid.org/0000-0001-9071-2842

\section{REFERENCES}

1 Fahey T, Montgomery AA, Barnes J, et al. Quality of care for elderly residents in nursing homes and elderly people living at home: controlled observational study. BMJ 2003;326:580-3.

2 Lloyd L, Banerjee A, Harrington C, et al. It is a scandal! Int J Sociol Soc Policy 2014;34:2-18.

3 Cooper C, Marston L, Barber J, et al. Do care homes deliver personcentred care? A cross-sectional survey of staff-reported abusive and positive behaviours towards residents from the MARQUE (managing agitation and raising quality of life) English national care home survey. PLoS One 2018;13:e0193399.

4 Natan MB, Lowenstein A, Eisikovits Z. Psycho-Social factors affecting elders' maltreatment in long-term care facilities. Int Nurs Rev 2010;57:113-20.

5 Pillemer K, Moore DW. Abuse of patients in nursing homes: findings from a survey of staff. Gerontologist 1989;29:314-20.

6 Fulop NJ, Ramsay AIG. How organisations contribute to improving the quality of healthcare. BMJ 2019;365:11773.

7 Gartshore E, Waring J, Timmons S. Patient safety culture in care homes for older people: a scoping review. BMC Health Serv Res 2017; $17: 752$

8 Emanuel L, Berwick D, Conway J. What Exactly Is Patient Safety? In: Advances in patient safety: new directions and alternative approaches. Vol 1, 2008. http://www.ncbi.nlm.nih.gov/pubmed/ 21249863

9 Braedley S, Martel G. Dreaming of home: Long-term residential care and (in) equities by design. Studies in Political Economy 2015;95:59-81.

10 Nygaard A, Halvorsrud L, Grov EK, et al. What matters to you when the nursing is your home: a qualitative study on the views of residents with dementia living in nursing homes. BMC Geriatr 2020;20:227.

11 Care Quality Commission. How CQC regulates: residential adult social care services provider Handbook, 2016. Available: http://www. cqc.org.uk/sites/default/files/20150327_asc_residential_provider_ handbook_appendices_march_15_update_01.pdf

12 Towers A-M, Smith N, Palmer S, et al. The acceptability and feasibility of using the adult social care outcomes toolkit (ASCOT) to inform practice in care homes. BMC Health Serv Res 2016;16:523.

13 SMITH N, TOWERS ANN-M, PALMER S, et al. Being occupied: supporting 'meaningful activity' in care homes for older people in England. Ageing Soc 2018;38:2218-40.

14 NHS Digital. Personal social services: staff of social services departments, England. London; 2018. https://files.digital.nhs.uk/CE/ 7525AE/NMDS Report 2018.pdf

15 Harrington C, Jacobsen FF, Panos J, et al. Marketization in long-term care: a Cross-Country comparison of large for-profit nursing home chains. Health Serv Insights 2017;10:117863291771053.

16 Vincent C, Burnett S, Carthey J. Safety measurement and monitoring in healthcare: a framework to guide clinical teams and healthcare organisations in maintaining safety. BMJ Qual Saf 2014;23:670-7. 
17 Arksey H, O'Malley L. Scoping studies: towards a methodological framework. Int J Soc Res Methodol 2005;8:19-32.

18 Cavalcante MLSN, Borges CL, Moura AMFTdeM, et al. Indicators of health and safety among institutionalized older adults. Rev EsC Enferm USP 2016;50:602-9.

19 Greenberg MD, Haviland AM, Yu H, et al. Safety outcomes in the United States: trends and challenges in measurement. Health Serv Res 2009;44:739-55.

20 Norton PG, Murray M, Doupe MB, et al. Facility versus unit level reporting of quality indicators in nursing homes when performance monitoring is the goal. BMJ Open 2014;4:e004488.

21 Dupler AM, Crogan NL, Short R. Pathways to quality improvement for boarding homes: a Washington state model. J Nurs Care Qual 2001;15:1-16. doi:10.1097/00001786-200107000-00003

22 Mueller C, Karon SL. ANA nurse sensitive quality indicators for longterm care facilities. J Nurs Care Qual 2004;19:39-47.

23 Oetjen RM, Zhao M, Liu D, et al. Nursing home safety: does financial performance matter? J Health Care Finance 2011;37:51-61-61.

24 Marlin D, Sun M, Huonker JW. Strategic groups and performance in the nursing home industry: a reexamination. Med Care Res Rev 1999;56:156-76.

25 Stevenson DG, Spittal MJ, Studdert DM. Does litigation increase or decrease health care quality? Med Care 2013;51:430-6.

26 Aronovitch SA. Falls and patient safety for older adults. Ostomy Wound Manage 2006:52:26, 28 passim:22-4.

27 Kosse NM, de Groot MH, Vuillerme N, et al. Factors related to the high fall rate in long-term care residents with dementia. Int Psychogeriatr 2015;27:803-14.

28 Bonner AF, Castle NG, Perera S, et al. Patient safety culture: a review of the nursing home literature and recommendations for practice. Ann Longterm Care 2008;16:18-22.

29 Carryer J, Weststrate J, Yeung P, et al. Prevalence of key care indicators of pressure injuries, incontinence, malnutrition, and falls among older adults living in nursing homes in New Zealand. Res Nurs Health 2017;40:555-63.

30 Estabrooks CA, Knopp-Sihota JA, Cummings GG, et al. Making research results relevant and Useable: presenting complex organizational context data to Nonresearch stakeholders in the nursing home setting. Worldviews Evid Based Nurs 2016;13:270-6.

31 van Nie-Visser NC, Schols JMGA, Meesterberends E, et al. An international prevalence measurement of care problems: study protocol. J Adv Nurs 2013;69:e18-29.

32 van Gaal BGI, Schoonhoven L, Hulscher MEJL, et al. The design of the SAFE or SORRY? study: a cluster randomised trial on the development and testing of an evidence based inpatient safety program for the prevention of adverse events. BMC Health Serv Res 2009;9:58.

33 Xu D, Kane R, Arling G. Relationship between nursing home quality indicators and potentially preventable hospitalisation. BMJ Qual Saf 2019;28:524-33.

34 Trinkoff AM, Lerner NB, Storr CL, et al. Leadership education, certification and resident outcomes in US nursing homes: cross-sectional secondary data analysis. Int J Nurs Stud 2015:52:334-44

35 Scott-Cawiezell J, Vogelsmeier A. Nursing home safety: a review of the literature. Annu Rev Nurs Res 2006;24:179-215.

36 Fleming A, Kydd A, Stewart S. Care homes: the developing ideology of a homelike place to live. Maturitas 2017;99:92-7.

37 Groenewoud AS, van Exel NJA, Berg M, et al. Building quality report cards for geriatric care in The Netherlands: using concept mapping to identify the appropriate "building blocks" from the consumer's perspective. Gerontologist 2008;48:79-92.

38 Fleming R. An environmental audit tool suitable for use in homelike facilities for people with dementia. Australas J Ageing 2011;30:108-12.

39 Hsieh YP, Hsieh YW, Lin CC, et al. A study on the formation of a measurement scale for the environmental quality of Taiwan's longterm care institutions by the Delphi method. $J$ Hous and the Built Environ 2012;27:169-86.

40 Recio-Saucedo A, Dall'Ora C, Maruotti A, et al. What impact does nursing care left undone have on patient outcomes? Review of the literature. J Clin Nurs 2018;27:2248-59.

41 Yu P, Qian S. Developing a theoretical model and questionnaire survey instrument to measure the success of electronic health records in residential aged care. PLoS One 2018:13:e0190749.

42 Barnett K, McCowan C, Evans JMM, et al. Prevalence and outcomes of use of potentially inappropriate medicines in older people: cohort study stratified by residence in nursing home or in the community. BMJ Qual Saf 2011;20:275-81.

43 O'Connor MN, Gallagher P, O'Mahony D. Inappropriate prescribing. Drugs Aging 2012;29:437-52.
44 Mamun K, Lien CTC, Goh-Tan CYE, et al. Polypharmacy and inappropriate medication use in Singapore nursing homes. Ann Acad Med Singap 2004;33:49-52.

45 Vermeulen JA, Kleefstra SM, Zijp EM, et al. Understanding the impact of supervision on reducing medication risks: an interview study in long-term elderly care. BMC Health Serv Res 2017;17.

46 O'Connor DW, D'Cunha C, Clifton T, et al. Quality indicators of psychotropic prescribing to people with dementia in aged psychiatry inpatient units. Aging Ment Health 2018;22:1-6.

47 Hillen JB, Vitry A, Caughey GE. Evaluating medication-related quality of care in residential aged care: a systematic review. Springerplus 2015;4:220.

48 Jaye C, Tordoff J, Butler M, et al. Quality in residential care: exploring residents', family members', managers' and staff perspectives. Qual Ageing Older Adults 2016;17:253-62.

49 Department of Health and Social Care. The adult social care outcomes framework 2018/19: Handbook of definitions. London; 2018.

50 Netten A, Burge P, Malley J, et al. Outcomes of social care for adults: developing a preference-weighted measure. Health Technol Assess 2012;16:1-165

51 Malley JN, Towers A-M, Netten AP, et al. An assessment of the construct validity of the ASCOT measure of social care-related quality of life with older people. Health Qual Life Outcomes 2012;10:21

52 Rand S, Malley J, Towers A-M, et al. Validity and test-retest reliability of the self-completion adult social care outcomes toolkit (ASCOT-SCT4) with adults with long-term physical, sensory and mental health conditions in England. Health Qual Life Outcomes 2017; 15:163

53 Winters S, Kool RB, Klazinga NS, et al. The influence of corporate structure and quality improvement activities on outcome improvement in residential care homes. Int J Qual Health Care 2014;26:378-87.

54 Triemstra M, Winters S, Kool RB, et al. Measuring client experiences in long-term care in the Netherlands: a pilot study with the consumer quality index long-term care. BMC Health Serv Res 2010;10:95

55 Wells Y, Fetherstonhaugh D, Solly KN. Development of a consumer experience reporting questionnaire for residential aged care homes in Australia. Australas J Ageing 2019;38:267-73.

56 Brazil K, Maitland J, Ploeg J, et al. Identifying research priorities in long term care homes. J Am Med Dir Assoc 2012;13:84.e1-84.e4.

57 Johnsen HM, Fruhling A, Fossum M, et al. An analysis of the work system framework for examining information exchange in a healthcare setting. Communications of the Association for Information Systems 2016;39:73-95.

$58 \mathrm{Li} \mathrm{Y,} \mathrm{Cen} \mathrm{X,} \mathrm{Cai} \mathrm{X,} \mathrm{et} \mathrm{al.} \mathrm{Perceived} \mathrm{Patient} \mathrm{Safety} \mathrm{Culture} \mathrm{in} \mathrm{Nursing}$ Homes Associated With "Nursing Home Compare" Performance Indicators. Med Care 2019;57:641-7.

$59 \mathrm{Kim} \mathrm{H}$, Kovner C, Harrington C, et al. A panel data analysis of the relationships of nursing home staffing levels and standards to regulatory deficiencies. J Gerontol B Psychol Sci Soc Sci 2009;64:269-78

60 Sammer CE, Lykens K, Singh KP, et al. What is patient safety culture? A review of the literature. J Nurs Scholarsh 2010;42:156-65

61 Yeung K-C, Chan CC. Measuring safety climate in elderly homes. $J$ Safety Res 2012;43:9-20.

62 Sorra J, Gray L, Famolaro T. AHRQ Nursing Home Survey on Patient Safety Culture: User's Guide. Rockville, MD, 2016.

63 Bonner AF, Castle NG, Men A, et al. Certified nursing assistants perceptions of nursing home patient safety culture: is there a relationship to clinical outcomes? J Am Med Dir Assoc 2009;10:11-20.

64 Sorra J, Gray L, Streagle S, et al. AHRQ Hospital Survey on Patient Safety Culture: User's Guide, 2016.

65 Estabrooks CA, Squires JE, Cummings GG, et al. Development and assessment of the Alberta context tool. BMC Health Serv Res 2009;9:1-12.

66 Pickering CEZ, Nurenberg K, Schiamberg L. Recognizing and Responding to the "Toxic" Work Environment: Worker Safety, Patient Safety, and Abuse/Neglect in Nursing Homes. Qual Health Res 2017;27:1870-81.

67 Hutchinson AM, Milke DL, Maisey S, et al. The resident assessment Instrument-Minimum data set 2.0 quality indicators: a systematic review. BMC Health Serv Res 2010;10:166.

68 Saliba D, Buchanan J. Development and validation of a revised nursing home assessment tool: MDS 3.0. Los Angeles, 2008.

69 Cranley LA, Norton PG, Cummings GG, et al. SCOPE: safer care for older persons (in residential) environments: a study protocol. Implementation Science 2011;6:71. 
70 Beuscher L, Grando VT. Challenges in conducting qualitative research with individuals with dementia. Res Gerontol Nurs 2009;2:6-11.

71 Hellström I, Nolan M, Nordenfelt L, et al. Ethical and methodological issues in interviewing persons with dementia. Nurs Ethics 2007;14:608-19.

72 Hubbard G, Downs MG, Tester S. Including older people with dementia in research: challenges and strategies. Aging Ment Health 2003;7:351-62.

73 Lloyd V, Gatherer A, Kalsy S. Conducting qualitative interview research with people with expressive language difficulties. Qual Health Res 2006;16:1386-404.

74 Moore TF, Hollett J. Giving voice to persons living with dementia: The researcher's opportunities and challenges. Nurs Sci $Q$ 2003;16:163-7.

75 Nygård L. How can we get access to the experiences of people with dementia? Scand J Occup Ther 2006;13:101-12.
76 Smith N, Towers A-M, Razik K. Adult social care outcomes toolkit (ASCOT CH3 guidance, V1.0). Canterbury: Personal Social Services Research Unit, University of Kent, 2017.

77 Caiels J, Rand S, Crowther T, et al. Exploring the views of being a proxy from the perspective of unpaid carers and paid carers: developing a proxy version of the adult social care outcomes toolkit (ASCOT). BMC Health Serv Res 2019;19:1-11.

78 Rand S, Caiels J, Collins G, et al. Developing a proxy version of the adult social care outcome toolkit (ASCOT). Health Qual Life Outcomes 2017:15:108

79 Rand SE, Caiels J. Using proxies to assess quality of life: a review of the issues and challenges. Canterbury Personal Social Services Research Unit, University of Kent; 2015.

80 Parker V, Engle RL, Afable MK, et al. Staff-perceived conflict between Resident-centered care and quality in the skilled nursing facility: are both possible? Clin Gerontol 2019;42:267-76. 